\title{
ANotify: A Fingerprint Biometric-Based and Attendance Web-Based Management System with SMS Notification for Industrial Sector
}

\author{
Mohd Nizam Osman ${ }^{*}$, Khairul Anwar Sedek ${ }^{2}$, Mushahadah Maghribi ${ }^{3}$, Nadia Hidayah \\ Mohd Faisal ${ }^{4}$ \\ ${ }^{1,2,4}$ Universiti Teknologi MARA, Perlis Branch, 02600 Arau, Perlis \\ ${ }^{3}$ Politeknik Tuanku Syed Sirajuddin, 02600 Arau, Perlis, Malaysia \\ Corresponding author: *mohdnizam@perlis.uitm.edu.my \\ Received Date: 3 September 2018 \\ Accepted Date: 8 October 2018
}

\begin{abstract}
Managing people is a difficult task and maintaining the attendance record is an important factor for most of the organizations. Meanwhile, in the industrial sector, a precise attendance record system of the employees is important for companies, especially for the payroll process. There are various existing technology that has been implemented to help an industrial sector to manage their attendance records. The use of current technology such as fingerprint biometric scanner and mobile devices as a complement to the software development will benefits to the industrial sector in order to enhance their services. This paper described a fingerprint biometric-based and web-based management system integrated with short message service (SMS) notification for attendance records of the employees known ANotify. It was specifically developed for an industrial sector that uses fingerprint as biometric features for employee attendance, is able to store records of employees' attendance in organized, systematic, and the SMS alert notification to the supervisors about the employee attendance reports. This system was developed based on System Development Life Cycle (SDLC) as a methodology. A user acceptance test was conducted with thirty (30) respondents to determine the effectiveness of the system by evaluating the questionnaire which was categorized into three (3) parts included user interface satisfaction, perceived ease of use, and integration of SMS notification. Results of the system evaluation showed that the system has a positive impact and to be well accepted by users, convenient, economic and reliable method of notification for the attendance records.
\end{abstract}

Keywords: Fingerprint biometric-based, Web-based management system, SMS notification, SDLC, user acceptance test.

\section{INTRODUCTION}

In the industrial sector, a precise attendance record system of employees is important for companies. For instance, managing time-attendance for multiple departments, sections, designations and grades is a paramount yet critical challenge. Furthermore, it becomes a cumbersome task to capture the timeattendance rules of an industrial sector and automate them.

Managing people is a difficult task for most of the industrial sectors, especially the management of attendance records. Meanwhile, maintaining the attendance record is an important factor, especially for the overtime claims, payroll and leave. Currently, most of the industrial company uses a punch-card system to record attendance of the employees. The punch-card system will only be able to record the attendance of the employees on the card and need to record them manually as the system is unable to record the attendance automatically. Thus, it is difficult for the human resource (HR) practitioner who is responsible of managing the attendance records to have an organized as they have to manually record the 
attendance. On top of that, supervisors who were responsible in supervising their employees are also not constantly notified and reported with the current updates on their employees' attendance record by the HR department. Therefore, the process of attendance record required an improvement and good monitoring system.

There are many different types of categories and various existing technologies that have been implemented to help industrial sectors to manage their attendance record and reports. According to (Shakil \& Nandi, 2013) defined that the attendance system can be derived into four categories, which includes manual system, biometric system, card-based system or known as Radio based Frequency Identification (RFID), and e-commerce system. Meanwhile, the most common technology used to record the attendance of the employee is by using RFID (Ansari, Navada, Agarwal, Patil, \& Sonkamble, 2011; Arulogun, Olatunbosun, Fakolujo, \& Olaniyi, 2013; Patil, 2017) and biometric tools (Kar, Debbarma, Saha, \& Pal, 2012; Patel, Kumar, Garg, \& Kumar, 2018). Biometric tools identify and recognize users by comparing biometric characters such as fingerprint, face and iris image. Meanwhile, RFID combines radio frequency and microchip technologies to create a smart system that can be used to identify, monitor, secure and do object inventory.

The earlier studies shown that Management Information System (MIS) could be used to manage the attendance record of employees, expected to accelerate the processes and services to customers (Shoewu, Olaniyi, \& Lawson, 2011). Meanwhile, the used of the web-based system become a popular trend due to the services can be accessed remotely by using web browser and can be accessible from anywhere in the world. Web-based application has been used in many sectors (Ko, Chen, Chen, Zhuang, \& Tan, 2001) (Barquest et al., 2018) and gives many benefits to the users such as ease of access and ease of use as the Internet is accessible worldwide. Besides, SMS technology becomes prevalence because most people often used mobile phone that gives convenience to the users who are familiar with SMS technology. Hence, a mobile phone is an essential medium to communicate, interact or device to gain knowledge (Asmara \& Aziz, 2011). The combination between web-based application and SMS technology has been implemented into the wide-range different sectors, such as education (Maghribi, Osman, \& Zainal, 2017; Vera \& Comendador, 2016; Verma \& Gupta, 2013), health organization (Gurol-Urganci, de Jongh, Vodopivec-Jamsek, Atun, \& Car, 2013; Wang \& Andoh-Baidoo, 2017), government (Onashoga, Ogunjobi, Ibharalu, \& Lawal, 2016; RoshanTharangga et al., 2013) and private sectors (Fleischer, Nelson, Sowah, \& Bremang, 2012; Osman et al., 2017).

Nowadays, SMS technology can be implemented with the web-based system in the more convenient way. SMS text message is also possible to be send from computer to recipients by using GSM modem and SMS gateway as a transmitting device. The changed from the traditional attendance management system to the digital system is predictable in industrial sector. Currently, the attendance records services are given based on the punch-card system, which includes a lot of time and resources, need to be considered by the HR practitioners. Therefore, the fingerprint biometric-based and attendance web-based management system with SMS notification was proposed and supported the HR practitioners in managing employees' attendance record, which support the satisfactory service to its customer and support the industrial's operational processes.

In this paper, the main sections are organized as follows: section 2 provides the methodology of the proposed work. In section 3, discusses the results based on the experiment conducted. Finally, section 4 concludes the paper. 


\section{METHODOLOGY}

\section{Developing the System Architecture for ANotify System}

Figure 1 illustrates the system architecture for the fingerprint biometric-based and web-based management system with SMS notification. Basically, the system consists of fingerprint biometric scanner, a web server to store databases, SMS gateways, and mobile phone.

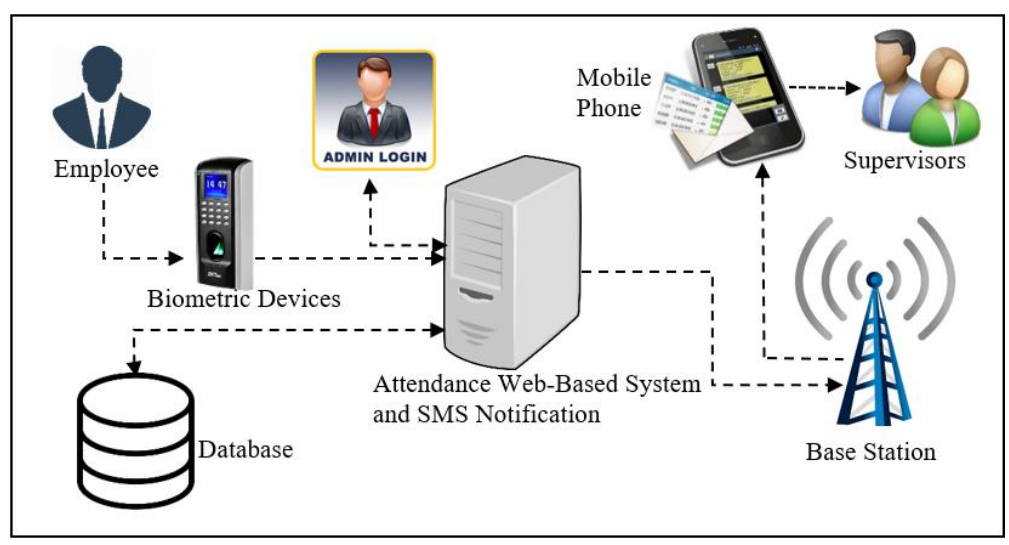

Figure 1: Fingerprint Biometric-Based and Attendance Web-Based Management System with SMS Notification Architecture

ANotify system is a web-based attendance management system which records the attendance data of employees using fingerprint biometric scanner and generates various reports for further actions. It enables human-resource (HR) practitioners as administrator to login from any device to check the employee's attendance record form anywhere at any time. Besides, HR practitioners can alert the supervisors automatically using SMS on any lateness or absenteeism in almost real time.

Fingerprint biometric scanner is used for capturing the fingerprint by recording and comparing biometric characteristics of employees. This devices store and record the attendance of the employees. Then, the data of attendance records will be used in the attendance web-based management system that resides in the web server. HR practitioners as administrator need to login in order to access the web-based and able to send SMS alert to the respective supervisors using SMS gateway. The supervisors will receive the message on their mobile phone.

\section{Model Used for the Developing of ANotify System}

The System Development Life Cycle (SDLC) was used to develop the ANotify system. SDLC is a project management model that defines the stages involved in bringing a project from inception to completion. It is a systematic approach which explicitly breaks down into six stages include system planning, system analysis, system design, system implementation, system integration and testing, and system operation and maintenance.

\section{System Planning}

In this phase, all information, data and problems about the project were gathered by read articles, journal, and thesis from previous research. A problem was recognized to address the requirements and opportunities that can be accomplished and reached in a project by conducted a group discussion meeting 
with supervisors and HR practitioners. Besides, the preliminary investigation was conducted by focusing on the attendance records of employees in the industrial sector to determine the problem statement, objectives, constraints, and security of the system are also considered. On top of that, the current technology was observed in order to understand how technology can be implemented during the project development. The feasibility report for the entire project was obtained after completed this phase.

\section{System Analysis}

From the information gathered, all requirements and opportunities were recognized. The aims to find the core problems and constraints occurred on the current attendance management system by analysed the current attendance management system workflow, attendance management procedures and attendance management data processing. Then, formulate goals of analysis construction, and system development that focuses on web-based attendance management system, fingerprint biometric-based and SMS technology. Besides, the activities included were the identification of the hardware and software requirements in the development system, scope of project, schedule of activities such as gantt chart and the total budget. The result of this phase is a logical system design.

\section{System Design}

The logical design from the previous phase was converted into physical system design. In this phase, the researcher designed a detailed requirement needed to solve the original problem in system development. There are several tools and techniques used for describing the system design of the proposed system. Included were the system components, system architecture, contextual diagram, data flow diagram, entity relationship diagram, databases, user interfaces design and system flowchart.

\section{System Implementation}

Layouts of interfaces for the web-based development were created using HTML and PHP coding through Adobe Dreamweaver CS6 and notepad++. PHP language is used to execute the system and MySQL is used for the database, while Apache runs as a web server software using Xampp package. Then, SMS Gateway script by iSMS was embedded in the web-based to make the system able to send the message to the customer's mobile phone. Meanwhile, for capturing the fingerprint, a fingerprint biometric scanner was used. After capturing the fingerprint, system matches this captured data with the data stored in the memory chip. If it is matched, the attendance is automatically recorded for the workers. Then, the attendance data was transformed into Microsoft excel (.csv) format and used in the attendance web-based management system as input purposes and store in the database.

In the development SMS system notification, the researcher was used SMS gateways and mobile phone, which are connected to the web-based system. The SMS gateways served as the gateway to connect with the mobile phone users and the system for sending the alert message automatically to the supervisors about the status of the employees under his/her supervision. The mobile phone was used for receiving the text messages and alert messages about the employees' status from the system.

\section{System Testing}

Before actually implementing the new system into operations, a debugging and testing of the program for fixing bugs or errors of the design were done. Free from error is a necessary testing to find errors that may occur as in the language error, logic errors and error analysis program. After codifying the whole programs of the system, a test plan was developed and run on a given set of test data. The system was evaluated to determine the system performance and to ensure all requirements accomplished. User acceptance testing was done by testing the system on users to ensure that users can perform the tasks respectively.

The system was tested and conducted at one of the industrial companies at Kulim, Kedah. The target respondents of this study were HR practitioners and supervisors who supervised a few workers under 
his/her supervision. In order to evaluate the effectiveness of the system, user acceptance testing was conducted. A quantitative research approach has been used for data collection by providing a survey questionnaire to the respondents. A total of thirty (30) survey questionnaires were distributed and received for the analysis. The questionnaire consists of eighteen (18) questions and categorized into three (3) parts. The first part was comprised of user interface satisfaction (UIS). The second part of the questionnaire investigates the perceived ease of use (PEU), whereas the third part, evaluate the integration of SMS notification (ISN). The data were analysed using arithmetic mean technique based on the ranking score value. Then, overall mean was calculated and classified into three categories, which is negative, neutral and positive based on the range of mean value in between zeros to five as shown in Table 1 .

Table 1: Range of mean value

\begin{tabular}{cc}
\hline Category & Range of Mean \\
\hline Negative & $0.00-1.66$ \\
Neutral & $1.67-3.33$ \\
Positive & $3.34-5.00$ \\
\hline
\end{tabular}

\section{System Operation and Maintenance}

After testing phase, minor refinement was done to integrate corrections of bugs and the user's feedback which was focused mainly on fine-tuning of system, configuring, installing and usability issues. It must meet the scope of any future enhancement, future functionality and any other added functional features to cope up with the latest future needs.

\section{RESULTS AND DISCUSSION}

\section{Interfaces of the ANotify Application}

This section explains about the interfaces of ANotify system. Figure 1 shows the main interface of the system. The button list was displayed on the left side of the page which contains Add New Employee, Employee List, Search, Add New Supervisor, Supervisor List, Import File in Database, Latecomers, Not Checked Out List and SMS Balance. When users click on the selected button list, it will be redirected to the specific menu as follows:

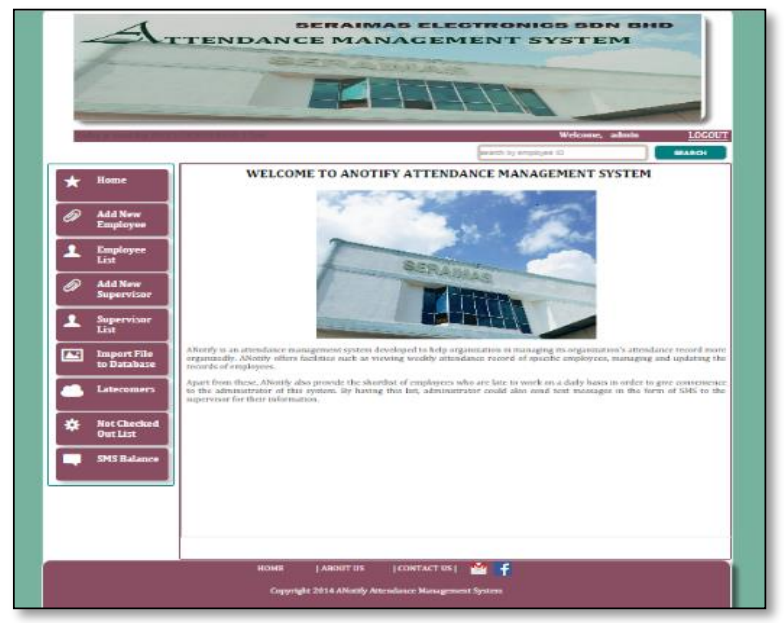

Figure 2: Main Interface for ANotify System 


\section{Add New Employee}

The user was able to add new record of the employee by filling the form provided.

\section{Employee List}

Link to the list of personal details of the current employees. Besides, there was an edit button available, which directs the user to edit certain information of the employee. The delete button was available for user to delete the record of selected employees.

\section{Search}

To search employee's information and the attendance record of employees. User required to key in the ID of the employee and click search. The result from the search process, displayed the information about the employee together with the supervisor ID associated with it.

\section{Add New Supervisor}

Enable a user to add new record of the new supervisor by filling the form provided.

\section{Supervisor List}

It displayed a list of current supervisor's information working in the company. Besides, the user can edit and delete the record if needed.

\section{Import File in Database}

The user was able to import data stored in Microsoft Excel with the format .csv into the database by browsing the files and upload the selected file before uploading it. The record is updated, and the imported data is updated into the database too.

\section{Latecomers}

It displayed the list of employees who came late to work based on the current day. Then, the administrator was able to click on "Send SMS" on each employee to send an SMS alert to the supervisor of the employees in order to inform and alert the supervisor on the attendance record of the employee under his or her supervision. Figure 3 (a) and 3(b) show the interface of send SMS for latecomers.

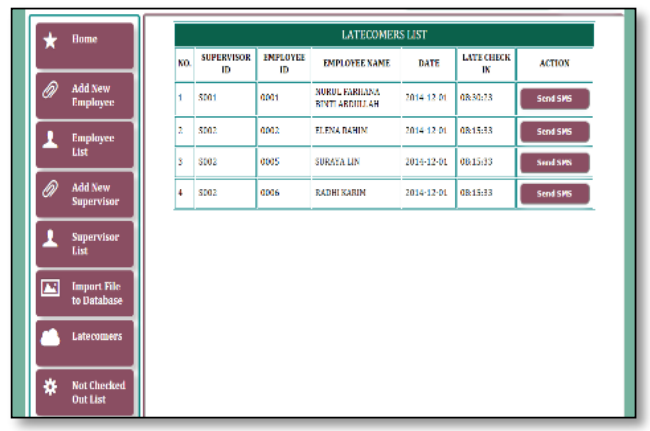

(a)

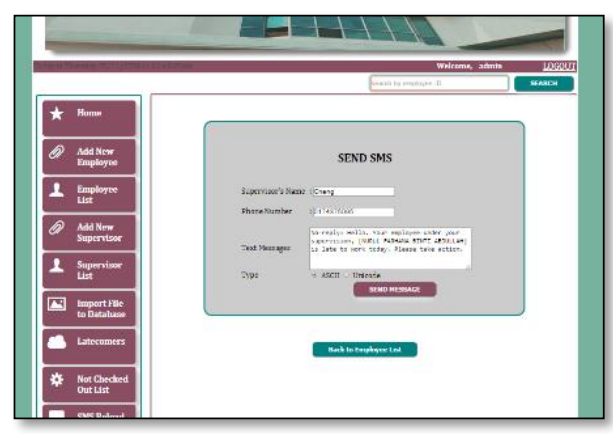

(b)

Figure 3: Interface of the application in (a) list of latecomers, (b) send SMS 


\section{Not Checked Out List}

The page displayed the list of employees who did not check out time after work in the attendance record. This function was provided in order to allow the administrator to monitor the number of employees who did not check out from work and send SMS text messages to the responsible supervisor for further action.

\section{SMS Balance}

It directs the user to another page, which displays the balance amount of SMS available in the user's iSMS account, which is provided by the SMS service provider.

\section{User Acceptance Test}

To evaluate the user acceptance test on ANotify system, the study was conducted to thirty (30) respondents of supervisors and HR practitioners from the industrial company. The experiment was conducted by given the participants opportunity to use and explore the system independently. Then, they were required to answer a set of questionnaires, which consist of eighteen (18) questions and divided into several categories. The study has successfully done to evaluate the effectiveness of the system and categorized into three parts, which includes user interface satisfaction (UIS), perceived ease of use (PEU) and integration of SMS notification (ISN). The score value with scale 1 to 5 was given for every type of criteria identified. Each scale represents from strongly disagree (1), disagree (2), neutral (3), agree (4) and strongly agree (5).

Table 2: The User Acceptance Test Results of the ANotify System

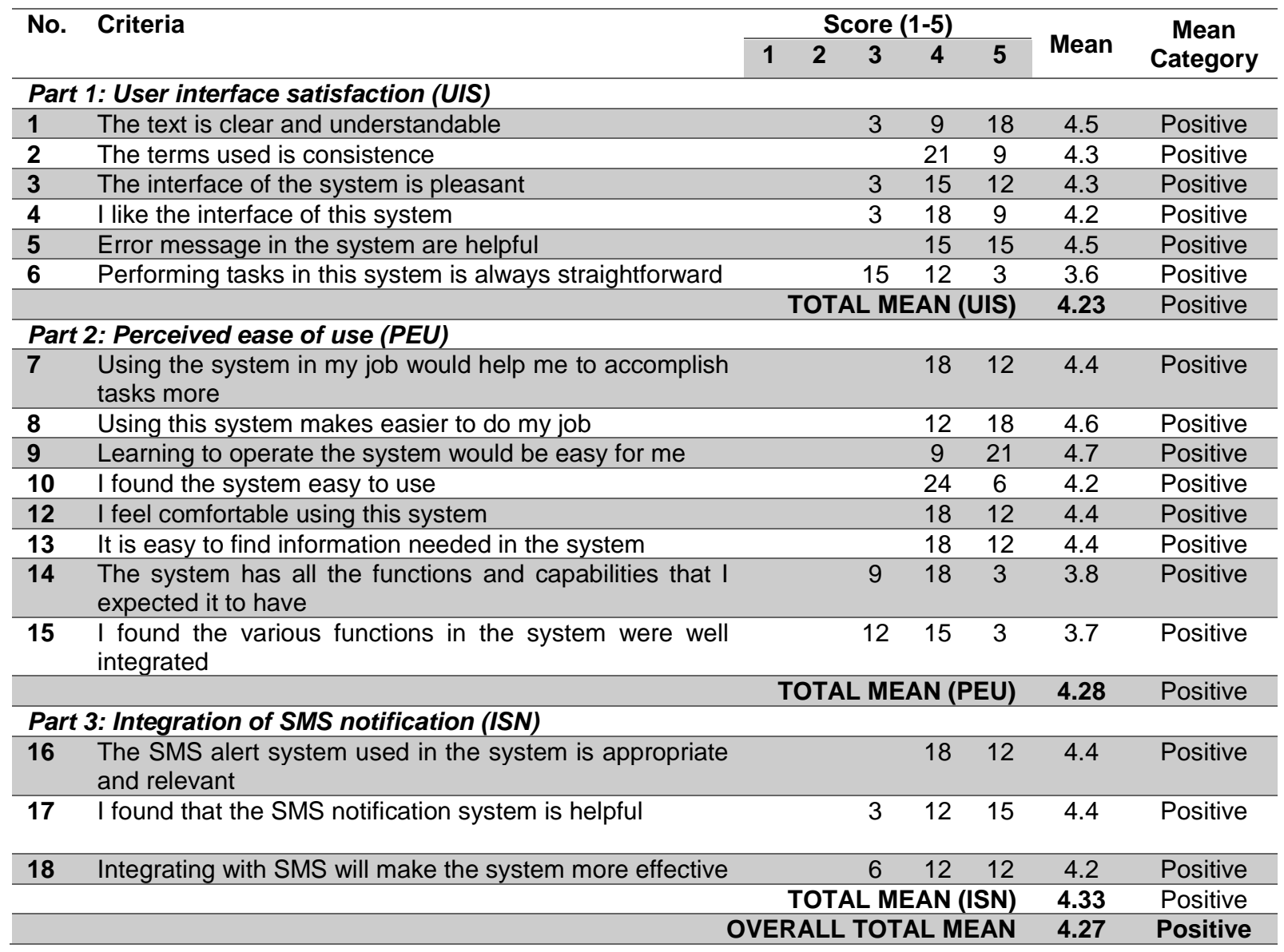


The study has successfully done for each type of the criteria to evaluate the effectiveness of the system. Table 1 summarized the results for the identified criteria and total means for each category respectively. The result shown that the target respondents were satisfied and positively accepted all functionalities provided by ANotify system. This can be proven when the mean for each category was calculated above the point of 4.0. Furthermore, the integration between attendance web-based management system and SMS alert function with the highest score 4.33 indicated that the participants were satisfied, and it can help them completed their task easier and faster. Meanwhile, the overall total mean for the user acceptance test was 4.27 which mean the positive feedback from the users. Therefore, this indicated that most of the users were accepted the ANotify system.

\section{CONCLUSION}

This paper successfully presents a solution of taking employee attendance for industrial sector using fingerprint biometric-based and web-based attendance management system with SMS notification. Hence, it shows some insight on user technology to construct and integrating the fingerprint biometric-based device, the web-based system with SMS technology to enhance the service for an industrial company. The system provides a lot of benefits to the users. For instances, the system provides employee's attendance record to the HR practitioners on the daily basis, the fingerprint biometric-based is secured, unique to each individual and cannot be shared, and employee's attendance notification to the supervisors through SMS system by sending a reliable message to alert about employees' attendance report under his/her supervision who is late to work and employee who did not check out from work on the previous day in order for the supervisors to take further action. Besides, the system provides a convenience way of notification through the use of mobile phone, which is a common personal communication medium in most of the employees. On top of that, the HR practitioners can easily monitor data from any remote location via web-based system and SMS technology.

To measure the effectiveness of the system, user acceptance testing was conducted to evaluate the performance of the system used questionnaire method. Performance evaluation results were encouraging with the overall system was measured to be positively acceptable by the users of the system. From the testing session, the system functions are well-functioned and can be achieved smoothly through the browser and mobile phone. Therefore, most of the respondents satisfied with the proposed system.

In conclusion, the fingerprint biometric-based and attendance web-based management system with SMS notification has a positive impact and to be well accepted by users, can overall improve management efficiency, cost effective, reliable, high scalability and modularity in order to enhance the productivity of the industrial sector.

\section{REFERENCES}

Ansari, A. N., Navada, A., Agarwal, S., Patil, S., \& Sonkamble, B. A. (2011). Automation of attendance system using RFID, biometrics, GSM Modem with .Net framework. In 2011 International Conference on Multimedia Technology (pp. 2976-2979).

Arulogun, O. T., Olatunbosun, A., Fakolujo, O. A., \& Olaniyi, O. M. (2013). RFID-based students attendance management system. International Journal of Scientific \& Engineering Research, 4(2), 19. 
Barquest, C., Corwin, M., Jung, P., Kiy, S., Lucow, K., Marcano, S., ... Tattan, D. (2018). Web-Based Control Room Applications at TRIUMF. Proceedings of the 9th Int. Particle Accelerator Conf., IPAC2018, Vancouver, BC, Canada.

Fleischer, P. B., Nelson, A. Y., Sowah, R. A., \& Bremang, A. (2012). Design and development of GPS/GSM based vehicle tracking and alert system for commercial inter-city buses. In 2012 IEEE 4th International Conference on Adaptive Science Technology (ICAST) (pp. 1-6).

Gurol-Urganci, I., de Jongh, T., Vodopivec-Jamsek, V., Atun, R., \& Car, J. (2013). Mobile phone messaging reminders for attendance at healthcare appointments. The Cochrane Database of Systematic Reviews, (12), CD007458.

Kar, N., Debbarma, M. K., Saha, A., \& Pal, D. R. (2012). Study of Implementing Automated Attendance System Using Face Recognition Technique. International Journal of Computer and Communication Engineering, 100-103.

Ko, C. C., Chen, B. M., Chen, J., Zhuang, Y., \& Tan, K. C. (2001). Development of a web-based laboratory for control experiments on a coupled tank apparatus. IEEE Transactions on Education, 44(1), 76-86.

Maghribi, M., Osman, M. N., \& Zainal, N. F. (2017). SMS-Based Content Alert: A Digital Library WebBased System Using SMS Technology. Jurnal Kejuruteraan, Teknologi Dan Sains Sosial, 3(2), 1-6.

Onashoga, A., Ogunjobi, A., Ibharalu, T., \& Lawal, O. (2016). A Secure Framework for SMS-Based Service Delivery in M-Government Using a Multicast Encryption Scheme. African Journal of Science, Technology, Innovation and Development, 8(3), 247-255.

Osman, M. N., Maghribi, M., Zain, N. M., Paidi, Z., Sedek, K. A., \& Yusoff, M. N. (2017). Online Car Rental System using Web-Based and SMS Technology. Journal of Computing Research and Innovation, 2(3), 33-38.

Patel, S., Kumar, P., Garg, S., \& Kumar, R. (2018). Face Recognition based smart attendance system using IOT. International Journal of Computer Sciences and Engineering, 6(5), 871-877.

Patil, D. P. (2017). Online Attendance Management System Using RFID with Object Contradict, (10), 4.

RoshanTharangga, J. ., Samarakoon, S. M. S. ., Karunarathne, T. A. ., Liyanage, K. L. P. ., Gamage, M. P. A. ., \& Perera, D. (2013). Smart attendance using real time face recognition - Google Search. In SAITM-RSEA 2013 (pp. 41-44).

Shakil, M., \& Nandi, R. (2013). Attendance Management System for Industrial Worker Using Finger Print Scanner. Global Journal of Computer Science and Technology: Graphics \& Vision, 13, 33.

Shoewu, O., Olaniyi, O. M., \& Lawson, A. (2011). Embedded Computer-Based Lecture Attendance Based Lecture Attendance Management System. African Journal of Computing \& ICT, 4(3), 27-36.

Vera, M. C. S., \& Comendador, B. E. V. (2016). A Web-Based Student Support Services System Integrating Short Message Service Application Programming Interface. International Journal of Future Computer and Communication, 5(2), 77-82. 
Verma, P., \& Gupta, N. (2013). Fingerprint Based Student Attendance System Using GSM. International Journal of Science and Research (IJSR), 2(10), 128-131.

Wang, Y., \& Andoh-Baidoo, F. (2017). Design of Integral Reminder for Collaborative Appointment Management. In Proceedings of the 50th Hawaii International Conference on System Sciences (pp. 910-919). 